\title{
Physical Education is the Basic Foundation to Build High Performance Athlete
}

\author{
Rajesh Kumar \\ Principal and Head University College of Physical Education \\ Osmania University \\ Hyderabad, Telangana State, India \\ rajesh2sports@gmail.com
}

\begin{abstract}
- school health and physical education programs, for kindergarten through high school, and local youth sports programs, need to implement a long-term athletic development to have a basic foundation of Physical Education to build High Performance Athlete. Physical Education plays the main role in the Identification of Talent and Selection of Sport of a Child at School and College level to guide for the correct coaching in becoming the future champions of the country. Sport programs and coaches resort to overemphasizing competition and related sport skills. From a coach's standpoint, there is need for practical, functional, and sequential athlete document that will provide coaches with best practices for the development of strength, flexibility, and stability in their athletes at correct age at school level to develop the motor qualities and skills. This Program of Physical Education must include movement vocabulary, physical literacy, and athletic movement skills, if athleticism is to be achieved. The Study has conducted among the 30 International level Sports of Telangana State Persons through the Questionnaire those who have participated in Olympics, Asian Games and Other International Tournaments. All the Sports Persons has recommended they become high performance athlete due to the Physical Education Programs in early age and at school level. Hence it is recommended that Physical Education is a basic foundation to build High Performance athlete.
\end{abstract}

Keywords—physical education, talent, selection of sport

\section{INTRODUCTION}

School health and physical education programs, for kindergarten through high school, and local youth sports programs, need to implement a long-term athletic development to have a basic foundation of Physical Education to build High Performance Athlete. Physical Education Plays the main role in the Identification of Talent and Selection of Sport of a Child at School and College level to guide for the correct coaching in becoming the future champions of the country.

Sport programs and coaches resort to overemphasizing competition and related sport skills. From a coach's standpoint, there is need for practical, functional, and sequential athlete document that will provide coaches with best practices for the development of strength, flexibility, and stability in their athletes at correct age at school level to develop the motor qualities and skills. This Programme of Physical Education must include movement vocabulary, physical literacy, and athletic movement skills, if athleticism is to be achieved.
The goal of Physical education is to prepare students for a Life time of Healthy living, Physical training for the all around development of the Child.

A long-term commitment to physical education, proper training to improve athleticism, and sport skill development is vital to produce optimal athletic potential. Proper training and athletic development require time.

As Per National Strength Conditioning Association the "Physical Literacy is a fundamental and valued human capability that can be described as a disposition acquired by human individuals encompassing the motivation, confidence, and physical competence that establishes purposeful physical activity as an integral part of their lifestyle,"

Athleticism is the result of athletic movement skills development that involves learning proper techniques for agility, balance, coordination, flexibility, metabolic training, power, reaction time, speed, strength, and strength endurance can be developed through physical education.

\section{A. Talent Development}

Scientific research concludes that it takes $8-12$ years of training for a talented athlete to reach elite levels. It also can be argued that it takes that long, if not longer, to produce quality youth coaches who understand how to develop proper skills in children. There are no shortcuts to athletic success Unfortunately, some coaches and parents overemphasize competition, while at the same time, approach proper movement skills and development to improve athleticism with little or no interest.

School sport offers the school community opportunities to build a strong identity and culture of excellence. Traditional values of respect, fairness, responsibility and resilience are developed as part of students' participation. School sport is often a partnership between the school and local community organisations, which work together to develop students' abilities and foster student aspirations for interesting and rewarding lives.

The mandated time allocations for physical and sport education for all students in Years $\mathrm{P}-10$ in government schools are as follows: Primary schools: $\bullet$ Years P-3: 20 to 30 minutes of physical education a day. - Years $4-6$ : three hours per week of physical education and sport with a minimum provision of 50 per cent for physical education. Secondary schools: • Years 7-10: 100 minutes per week for physical education 
Sporting activity allows each individual to meet primary human needs: the basic biological need for movement and play, the need for safety, order, belonging and love, esteem and self-actualization. 2. Sport and sport activities significantly affect the desirable psychosomatic development of children and young people, they

According to Balyi, his theoretical model can, when properly implemented, provide a change in sports programs and athletic development by identifying gaps, and providing guidelines for movement problem solving, improving performance at various stages of athletic development, and outlining a framework to develop physical literacy, physical fitness for life, and competitive athletics

A well-planned and balanced schedule of training, practice, competition, and recovery will enhance optimum development throughout the individual's athletic career.

\section{B. Importance of Coach Education}

The following list of program components contains a series of movement component categories that correspond and expand the physical literacy and movement foundation:

- Balance and stability

- Fundamental/dynamic movement

- Object control

- Plyometrics

- $\quad$ Speed and agility (multidirectional)

- Fun drills

- Strength/endurance/power

\section{METHODOLOGY}

The Study has conducted among the 30 International level Sports Persons of Telangana State through the Questionnaire those who have participated in Olympics, Asian Games and Other International Tournaments . The International Players are from Badminton( 8 Players) Athletics (8) Cricket (4) Foot Ball (3) Volley Ball (4) Basket Ball Players (3). All the Players has given the Questionnaire prepared by the Researcher in consultation with Coaches and former Players. All the Players are also taken Interview also.

All the International Sports Players has claimed that the Physical Education Teacher in Schools has motivated and coach them to participate in Sports events at School level. The findings reveal that schools draw on an extremely varied range of strategies to identify and develop their talented pupils in physical education. Although the majority of schools appear to have developed a whole school and departmental policy for developing talent, there was a strong indication that a whole school policy was a significant driving force for designing a policy at department level. Although there has been a great deal of research on talent development in sport and education, there has been a distinct lack of research on developing talent specifically in a curricular physical education context. The most common criteria for assessment were reported to be performance in school sport and club sport. A key finding was that the majority of subject leaders indicated that the main area of expertise for staff was games activities, which may have significance if teachers feel better able to identify talented pupils in areas in which they themselves have expertise.

\section{CONCLUSION}

The paper concludes with a discussion of the implications of these findings, suggesting that instances of good practice need to be highlighted and widely disseminated, and detailed guidance should be made available to all schools, if effective and equitable talent development practices are to be properly adopted within physical education departments. Authors and Affiliations

\section{RECOMMENDATIONS}

Overall, the findings suggest that the effectiveness of Physical Education Programmes at School Level. The Talent Identification of Child will be at Physical Education Programme. Physical Literacy training is very important for Child at School Level. The Selection of Sport can be done through Physical Education. Hence Physical Education is the basic foundation to build high.

\section{ACKNOWLEDGMENTS}

I am thankful to Coaches and International Players for giving there valuable time in completion of the Study.

\section{REFERENCES}

[1] I. Balyi, "Sport System Building and Long Term Athlete Development in Canada, The Situations and Solutions, Coaches Report," The Official Publication of the Professional Coaches Association 8(1): 25 28, 2001.

[2] L. Meadors, "Practical Application for Long-Term Athletic Development," National Strength Conditioning Association

[3] Charles A. Bucher and Deborah A. Dvest, Foundations of Physical Education and Sports, Englewood Cliffs, N.J: Prentice Hall, Inc. 1982.

[4] Alison L. Parratt, "Indoor games and Activities, A comprehensive guide to the teaching of Games skills to pupils of seven to thirteen years," 1983. 